\title{
Los estereotipos de género en las elecciones y expectativas de estudiantes de Educación Técnica Profesional en Argentina: diferencias regionales y de género
} Gender Stereotypes in the Elections and Expectations of Professional Technical Education Students in Argentina: Regional and Gender Differences

\author{
Ada Freytes Frey y Pablo Barbetti ${ }^{1}$
}

\begin{abstract}
Resumen
A pesar de que en los últimos años en Argentina se amplió paulatinamente el acceso de estudiantes mujeres a la Educación Técnico Profesional, en la modalidad persisten importantes desigualdades de género. El presente trabajo tiene como objetivo analizar las motivaciones iniciales y las expectativas futuras de estudiantes que asisten a ofertas de la Educación Técnica Profesional y su relación con la persistencia -o con la transformación- de estereotipos sobre las diferencias de género en el mercado laboral.

El abordaje metodológico fue cuanti-cualitativo. Los datos fueron construidos a partir de la aplicación de encuestas y la realización de grupos focales con estudiantes varones y mujeres de Escuelas Secundarias Técnicas y de Cursos de Formación Profesional en dos regiones del país. Los resultados muestran diferencias significativas entre ambos territorios analizados y, al interior de estos, entre varones y mujeres. A pesar de las políticas en pos de la igualdad de género y la visibilización de las diversas discriminaciones que sufren las mujeres generada por las múltiples movilizaciones feministas en el último tiempo en la Argentina, siguen persistiendo imaginarios que legitiman las desigualdades.
\end{abstract}

Palabras clave

Género, educación técnica, formación profesional, motivaciones, expectativas, desigualdades.

\section{Abstract}

Despite the fact that in recent year in Argentina the access of female students to Vocational Technical Education has gradually expanded, in the modality there are still important gender inequalities. The purpose of this paper is to analyze the initial motivations and future expectations of students attending Professional Technical Education and their relationship with the persistence -or with the transformation- of stereotypes about gender differences in the labor market.

The methodological approach was quantitative and qualitative. The data wereconstructed from surveys and focus groups with male and female students from Technical Secondary Schools and Vocational Training Courses in two regions of the country. The results show significant differences between both territories analyzed and, within these, between men and women. In spite of the policies for gender equality and the visibility of the various discriminations that women suffer due to the multiple feminist mobilizations in recent times in Argentina, gender stereotypes that legitimize inequalities persist.

Keywords

Gender, technical education, professional training, motivations, expectations, inequalities.

\section{Cómo citar/Citation}

Freytes Frey, Ada; Barbetti, Pablo (2020). Los estereotipos de género en las elecciones y expectativas de estudiantes de Educación Técnica Profesional en Argentina: diferencias regionales y de género. Revista de Sociología de la Educación-RASE, 13 (3), 346-370. http://dx.doi. org/10.7203/RASE.13.3.17451.

\footnotetext{
1 Ada Freytes Frey, Universidad Nacional Arturo Jauretche (UNAJ) y Universidad Nacional de Avellaneda (UNDAV), afreytesfrey@undav.edu.ar; Pablo Barbetti, Universidad Nacional del Nordeste, pablobarbetti@hotmail.com.
} 


\section{Introducción}

Desde su adhesión a la Convención para la Eliminación de toda forma de Discriminación contra la Mujer (CEDAW en inglés) en 1985, la República Argentina ha implementado paulatinamente diversas políticas y cambios normativos con perspectiva de género. Este impulso por parte del Estado ha interactuado con las luchas en pos de un cambio cultural más profundo, impulsadas por los movimientos feministas expresados en distintas organizaciones y manifestaciones culturales. Las luchas por la igualdad de género $-\mathrm{y}$, más particularmente, por los derechos de las mujeres- se ha articulado, en este país, con otras expresiones sociales y políticas, como por ejemplo los movimientos sociales que han ganado creciente protagonismo en la esfera pública nacional desde fines de los años 90.

Las transformaciones en los imaginarios sociales promovidas por estas luchas se hicieron manifiestas en las multitudinarias movilizaciones de mujeres contra la violencia machista, bajo la consigna «Ni una menos», a partir del 3 de junio de 2015. Posteriormente, en 2018, las movilizaciones a favor de la despenalización del aborto mostraron, por un lado, cuánto había permeado la perspectiva de género el imaginario de las jóvenes -particularmente en la Ciudad de Buenos Aires, centro de resonancia de las manifestaciones públicas- y, al mismo tiempo, las diferencias culturales en relación al género en distintas regiones del país.

En lo que respecta a la Educación Técnico Profesional (ETP), si bien la modalidad recibió por parte de las políticas estatales un impulso considerable a partir de la sanción de la Ley de Educación Técnico Profesional (N. ${ }^{\circ}$ 26058) en 2005, fueron muy limitadas las intervenciones orientadas a reducir las desigualdades de género, ampliamente documentadas en esta modalidad. Esto parece haber empezado a cambiar recientemente, con la creación a fines de 2017 de la Comisión de Género dentro del Instituto Nacional de Educación Tecnológica ${ }^{2}$ (INET). Esta Comisión tiene como mandato específico «incorporar la perspectiva de género en la ETP en todo el sistema escolar (curricula escolar, prácticas escolares, infraestructura, cultura escolar)», e «incrementar la matrícula de mujeres en la ETP (principalmente en el nivel secundario)» $\aleph^{3}$.

Estos objetivos parten de la constatación de las importantes desigualdades de género que aún persisten en esta modalidad educativa, integrada por tres niveles: Secundario Técnico, Formación Profesional y Superior Técnico. En este artículo nos focalizaremos en los primeros dos. La Educación Secundaria Técnica (EST) fue planteada en sus comienzos como una «educación para varones». Si bien se ha ampliado paulatinamente el acceso de estudiantes mujeres a la modalidad, los últimos datos disponibles muestran que la igualdad está todavía distante: en 2016, solo el 32,5\% de estudiantes de EST eran mujeres (INET, 2018). Por el contrario, en la Formación Profesional (FP), la matrícula femenina supera a la masculina: $56 \%$ de mujeres, $44 \%$ de varones, para el mismo año. Estas cifras ocultan, sin embargo una desigualdad en la oferta de cursos, que se orientan diferencialmente hacia oficios y profesiones «típicamente masculinos» o «típicamente femeninos» (Millenaar y Jacinto, 2015; Millenaar, 2019). Tal segmentación por género también se observa en el nivel de EST, en el cual sigue habiendo importantes diferencias en la elección de las especialidades (Bloj, 2017). Por ejemplo, en Electromecánica y Electrónica/Energía, las mujeres solo alcanzan el 12\%, contra el 88\% de los varones. Mientras que en las especialidades más elegidas por las mujeres, Administración y Química, estas representan el 65\% y el 55\% de la matrícula respectivamente (INET, 2018).

\footnotetext{
2 El INET es a partir de 1995 el organismo del Ministerio de Educación de la Nación que tiene a su cargo la coordinación de las políticas públicas de ETP. Trabaja en forma articulada con las provincias, de quienes dependen directamente los centros educativos en la Argentina.

3 Disposición 118 APN-INET, de marzo de 2018.
} 
En este marco, surge la pregunta por los motivos que llevan a estas elecciones diferenciadas de varones y mujeres, que tienden a reflejar y perpetuar la división sexual del trabajo. También buscamos analizar en qué medida varones y mujeres tienen expectativas diversas con respecto a la Educación Técnico Profesional y cómo se relacionan tales motivaciones y expectativas con la persistencia -o con la transformaciónde estereotipos sobre las diferencias de género en el mercado laboral, en un contexto de cambio cultural.

Abordaremos estos interrogantes a través de un estudio comparativo en dos regiones de la Argentina, que presentan contrastes tanto en términos socio-económicos como culturales. Así como las desigualdades de género en la ETP no han estado en la agenda de las políticas públicas argentinas hasta años recientes, tampoco han sido motivo de investigación. Esto ha empezado a cambiar en las últimas décadas y comienza a construirse un conjunto interesante de trabajos (Pérez Moreno, 2012; Seoane, 2012; Jacinto, 2015; Jacinto y Millenaar, 2015; Bloj, 2017; INET, 2017 y 2019; Millenaar, 2017 y 1019). No obstante, todas estas investigaciones están focalizadas en términos geográficos, ya sea en la Ciudad de Buenos Aires o en el Gran Buenos Aires ${ }^{4}$. Sin embargo, la Argentina se caracteriza por su heterogeneidad, tanto socio-económica como cultural (con rasgos de apertura a los cambios en la zona central donde se concentra tanto la actividad productiva como una parte importante de la población y rasgos de conservadurismo en regiones del interior, particularmente el Noreste y el Noroeste). En este artículo buscamos comenzar a interrogar esa diversidad, mirando comparativamente dos regiones contrastantes.

\section{Diferencias por género en las elecciones y expectativas educativas: discusiones teóricas}

La persistencia de la segregación por género según distintas ramas de la educación técnico profesional, aún en países donde se ha logrado ampliar el acceso de las mujeres a dicha modalidad, ha sido señalada en distintos estudios (Evans, 2006; Martínez y Merino, 2011; Seoane, 2012; Martínez, 2019). Se ha constatado que las mujeres se orientan en mayor medida a especialidades y oficios ligados con lo administrativo, el cuidado de personas, la atención de la salud. En cambio, los varones tienden a ser mayoría en ramas ligadas a la tecnología y la manipulación de objetos. Esto tiene su correlato en el mercado laboral, donde se advierten dos modos de segregación que están en la base de las desigualdades de género: una segregación horizontal, que refiere a la concentración de mujeres en ciertas ocupaciones identificadas como «típicamente femeninas», y una segregación vertical que alude a la mayor presencia de mujeres en puestos de menor jerarquía (PNUD, 2011).

Los motivos y razones de estas elecciones de los/as estudiantes han sido objeto de discusiones teóricas, y existen distintas interpretaciones acerca de estas desigualdades. Desde la teoría del capital humano, se ha puesto el acento en la elección racional de hombres y mujeres, quienes tienen en cuenta las distintas condiciones que estos géneros encuentran en el mercado de trabajo (Becker, 1987). Desde esta perspectiva las elecciones se asocian a la evaluación que hacen hombres y mujeres, sobre la diferente rentabilidad que lograrían en la inversión educativa.

En lo que respecta particularmente a la segregación horizontal, se señala que el tipo de profesión que eligen las mujeres permite una mejor conciliación entre trabajo y vida familiar, en una organización social donde no hay igualdad de responsabilidades familiares, sino que la mujer debe hacerse cargo mayorita-

4 Una excepción es el trabajo de Pérez Moreno (2012), pero no presenta una comparación entre regiones, sino que está focalizado en una provincia del interior (Córdoba). 
riamente de estas últimas (Martínez, 2019). Este autor sostiene que: «No tenemos un sistema patriarcal que lleva a menos vocación de mujeres por la ciencia [y la tecnología], sino un mercado de trabajo que hace más difícil la conciliación en las ingenierías» (2019: 12). Por lo tanto, plantea la necesidad de tener en cuenta la interacción entre sistema educativo, mercado laboral y familia.

No obstante, si bien el concepto de sistema patriarcal ha sido utilizado de diversas maneras y ha sido motivo de controversias, desde una perspectiva de género, remite a las relaciones de poder y subordinación ligadas a la construcción social de la diferencia sexual (Millet, 1996; Scott, 1999). Estas relaciones se manifiestan en una multiplicidad de instituciones, que reproducen relaciones asimétricas y modelos culturales que legitiman dicha subordinación: la familia y el mercado laboral son dos de ellas, de central importancia -también el sistema educativo-. En tal sentido, las normas culturales que asignan a las mujeres la responsabilidad primaria sobre las tareas de reproducción del hogar y a los varones el rol de proveedor de la familia están en el corazón del sistema sexo/género (Rubin, 1986) que sostiene la persistencia de las desigualdades de género.

Por lo tanto, sin negar la capacidad de agencia y elección racional de las mujeres que subraya Martínez García, desde las teorías de género se plantea que en sus decisiones y preferencias no solo intervienen consideraciones ligadas al cálculo costo-beneficio y a la maximización de la utilidad individual o familiar, sino también modelos normativos que asignan a varones y mujeres distintos lugares en la división sexual del trabajo (Busso y Pérez, 2019). Por otra parte, en la propia organización del mercado de trabajo intervienen estos esquemas genéricos, que afectan también las decisiones de contratación de los empleadores. Se trata, como ha señalado Bourdieu (1999), de la correspondencia entre las estructuras objetivas del orden social y los esquemas subjetivos de percepción y valoración, que lleva a una naturalización de las desigualdades.

Diversos autores (como por ejemplo, Bourdieu, 1999; Butler, 2001) han señalado que en la construcción social de la diferencia sexual opera un conjunto de oposiciones que contribuye a construir una matriz de inteligibilidad binaria, que divide atributos y actividades entre lo masculino y lo femenino. Estas oposiciones están en la base de la constitución de estereotipos de género, esquemas de percepción, valores y normas arraigadas, que establecen roles y atributos cristalizados y diferenciados para varones y mujeres. En particular, los estereotipos de género establecen principios de división en relación al cuerpo, a las capacidades, a la dimensión afectiva y emocional y a las competencias comunicativas (Gutiérrez Esteban e Ibañez Ibañez, 2013).

En lo que respecta específicamente a la división sexual del trabajo, se ha señalado que los estereotipos que la fundamentan y legitiman se asientan en dos principios organizadores: un principio de separación por el que se delimitan tajantemente los trabajos de varones y mujeres, y un principio de jerarquización, por el cual se reconoce que hay trabajos que valen más que otros -y los trabajos realizados por varones suelen valer más que los de las mujeres- (Anzorena, 2013).

Así, desde un enfoque de género, es importante preguntarse por la persistencia de estereotipos de género que pueden intervenir en los procesos de elección y toma de decisión -en este caso, en relación a la educación técnico-profesional-. En esta línea, en una investigación que se preguntaba por los factores que intervienen en la aspiración de los/as jóvenes de seguir una carrera en ciencias o en ingeniería, se señalaba que las representaciones sociales que ligan estas ocupaciones con lo masculino generaba que muchas jóvenes sintieran que estas profesiones no eran para ellas (Archer, 2020; Moote, 2020). 
No obstante, los condicionantes de género no son los únicos que intervienen en tales procesos. Coincidimos con Tarabini y Curran (2015) en que el análisis de las decisiones educativas debe entenderse desde una perspectiva multidimensional. Los trabajos mencionados acerca de la elección de los/as jóvenes por una carrera en ciencia o en ingeniería muestran que en tales decisiones intervienen una multiplicidad de factores (Archer, 2020; Moote, 2020).

Es ya un tópico recurrente el análisis que las familias juegan en las elecciones educativas, a través de los recursos materiales y culturales que proveen -o la escasez de los mismos-, pero también de las aspiraciones y modelos de identificación que transmiten a los/as jóvenes (Archer, 2020; Merino, Martínez y Valls, 2020; Tarabini y Curran, 2015). En el caso específico de la ETP, diversos trabajos que, en Europa y en Latinoamérica, han puesto el foco en estudiantes mujeres que han elegido especialidades técnicas «atípicas» para su género (Evans, 2006; OIT, 2014; Perez Moreno, 2012) mencionan, entre los diversos motivos que favorecen tales elecciones, el peso de los antecedentes familiares y las experiencias que ellos han propiciado: padres que han ejercido esa especialidad o han estudiado en la escuela técnica; experiencias tempranas de manipulación de maquinaria o equipo técnico. Estas situaciones no siempre han implicado un apoyo familiar a sus decisiones: muchas veces, estas se tomaron a pesar de la resistencia de la familia, que sin embargo impulsaban la educación técnica para los hijos varones.

En los modelos que buscan explicar las desigualdades en las elecciones educativas, también juegan un papel importante los propios actores del sistema educativo. Archer y otras (2020) señalan que tanto las actitudes y prácticas de los/as docentes como los niveles de presentismo (o ausentismo) y la calidad de la enseñanza son elementos que influyen en las decisiones de los/as jóvenes por la ciencia, particularmente en estudiantes de clase trabajadora y de minorías étnicas. En su estudio, son importantes asimismo las estrategias institucionales (como por ejemplo, la presencia o no de clubes de ciencias y de instancias de orientación vocacional). Estas autoras señalan que las desigualdades (étnicas, de clase, de género) pueden ser amplificadas o disminuidas a nivel escolar mediantes prácticas de apoyo que sirvan para desafiar los prejuicios que llevan a los/as estudiantes a auto-excluirse del campo de las ciencias. En el caso de la educación técnico profesional en Argentina, existen investigaciones que dan cuenta de estrategias de selección explícitas, ligadas al género, en centros de FP. Algunas instituciones ofrecen los cursos exclusivamente a mujeres o varones, o bien, al momento de la inscripción se «sugiere» otra especialidad, más tradicional para el género (Millenar, 2017).

Merino, Martínez y Valls (2020) se refieren a este tipo de influencias escolares y familiares (también del grupo de pares) como el grado de heteronomía en las motivaciones de los/as estudiantes para elegir la Formación Profesional. A su vez, consideran que en la elección de la especialidad operan motivaciones de carácter instrumental -más ligadas a la utilidad de la inversión educativa, en la línea con la teoría del capital humano- y motivaciones que llaman expresivas, que tienen que ver con valores y significados compartidos. «La motivación expresiva se puede traducir con una identificación cultural asociada a un ethos profesional determinado» (2020: 263). Incluir lo expresivo supone tener en cuenta también deseos y emociones. Lo interesante es que estos autores encuentran que, en la elección de la Formación Profesional en Barcelona operan tanto motivaciones instrumentales como motivaciones expresivas en los mismos/as estudiantes. 


\section{Aspectos metodológicos y caracterización contextual}

Señalamos anteriormente que en este trabajo nos centraremos en dos de los tres niveles que integran la ETP en Argentina: la Educación Secundaria Técnica (EST) y la Formación profesional. Ambas presentan perfiles muy diferentes. La oferta de especialidades de EST es amplia y los títulos que otorga acreditan tanto la formación técnico profesional como el cumplimiento obligatorio del nivel secundario ${ }^{5}$. En tal sentido, la EST argentina tiene características particulares, porque buscó desde sus inicios integrar una educación científico-tecnológica de alto nivel con una formación que favoreciera la inserción en el mercado laboral. Por otra parte, nunca fue terminal: siempre habilitó para la continuidad de estudios terciarios o universitarios (Gallart, 2006) y, por sus niveles de calidad en la formación en ciencias básicas y exactas y en tecnología, es considerada una oferta educativa que prepara especialmente para el estudio universitario de este tipo de ciencias y de ingeniería. La enseñanza técnica aparece como más exigente que la de otras ramas de la educación secundaria, tanto por las materias teórico-técnicas vinculadas a sectores productivos específicos que involucra, como por los tiempos más extensos que prevé su curriculum (doble jornada, un año más de duración que las otras modalidades).

En esto, la EST contrasta con la Formación Profesional (FP), destinada desde sus orígenes a la capacitación de los trabajadores, con una impronta inicial de educación no formal y para adultos. En tal sentido, el nivel de FP se desarrolló como un sector marginal del sistema educativo, sin relación con el resto de las modalidades. En el contexto de la crisis del empleo y las políticas neoliberales de los años 90 la FP incorporó una lógica social, apelando a la formación en oficios como estrategia para compensar la situación de grupos específicos con problemas de empleo (Jacinto, 2015). En los últimos años, al adquirir las políticas de empleo un carácter más integral la FP se ha articulado con programas de terminalidad de la escuela secundaria, nivel obligatorio desde 2006. Se trata de una oferta formativa muy diferente de la anterior, organizada en diversidad de cursos correspondientes a distinta familias profesionales, cuya duración va desde unos pocos meses a dos años académicos como máximo.

Este artículo se enmarca en una investigación colaborativa más amplia realizada por una Red de Investigación y Docencia sobre Políticas de Inserción Educativa y Laboral de Jóvenes, de la que participaron equipos de investigación de cinco instituciones ubicadas en distintas regiones de la República Argentina ${ }^{6}$ (Ciudad Autónoma de Buenos Aires, Neuquén, Mendoza, Conurbano Bonaerense Sur y Corrientes). El objetivo de la misma era: analizar comparativamente cómo se producen, reproducen y transforman a nivel institucional las desigualdades entre varones y mujeres en EST y CFP de estas cinco regiones. En cada región se llevó a cabo una investigación con el mismo diseño y luego se realizaron comparaciones entre regiones. El presente artículo trabaja con datos construidos en relación a uno de los objetivos específicos: comparar las expectativas de formación e inserción laboral de estudiantes varones y mujeres, como así también sus experiencias en la institución, desde una perspectiva de género. Abarca dos de las regiones mencionadas, que, como veremos al final de este apartado, presentan características distintivas: la zona sur del Conurbano Bonaerense -es decir, los partidos de la Provincia de Buenos Aires que rodean la Capital Federal de la Argentina- y la provincia de Corrientes.

El diseño consistió en un estudio de casos múltiples, con un abordaje cuanti-cualitativo. En cada región se seleccionaron tres EST y tres centros de FP, tomando como criterio la selección de especialidades

\footnotetext{
5 Las escuelas técnicas están divididas en tres orientaciones principales: las agropecuarias, que constituyen el 29,5\%; las industriales el 61,6\% y las de servicios 8,9\% (INET, 2017).

6 La investigación se concretó gracias al financiamiento del Fondo Nacional de Investigaciones en Educación Técnico Profesional (FONIETP-INET).
} 
que presentaran un distinto balance de la matrícula según género (con predominio de varones, con cierto equilibrio y con mayor presencia de mujeres). Así, en Corrientes trabajamos con las especialidades Madera y Mueble (también por su relevancia en la región), Informática y Organización y Gestión, en tanto que en el Conurbano Bonaerense con Construcción, Informática y Química. Este artículo está basado en datos correspondientes al objetivo específico mencionado: encuestas a estudiantes (en EST de $4^{\circ}$ año - primer año del Ciclo Orientado, en el que se hace la elección de la especialidad ${ }^{7}$ - y en FP de cursos relacionados con las especialidades seleccionadas) y grupos focales ${ }^{8}$ con estudiantes del último año de EST y de los cursos de FP'.

Tabla I. Instrumentos de relevamiento de datos utilizados en ambas Regiones

\begin{tabular}{|c|c|c|c|c|c|c|c|c|c|c|c|}
\hline \multirow{3}{*}{$\begin{array}{l}\text { INSTRUMENTOS DE } \\
\text { RECOLECCIÓN DE } \\
\text { INFORMACIÓN }\end{array}$} & \multicolumn{5}{|c|}{ ESCUELAS SECUNDARIAS TÉCNICAS (EST) } & \multicolumn{6}{|c|}{ CENTROS DE FORMACIÓN PROFESIONAL (FP) } \\
\hline & \multicolumn{2}{|c|}{$\begin{array}{c}\text { CONURBANO } \\
\text { SUR }\end{array}$} & \multicolumn{2}{|c|}{ CORRIENTES } & \multirow{2}{*}{ TOTAL } & \multicolumn{3}{|c|}{$\begin{array}{c}\text { CONURBANO } \\
\text { SUR }\end{array}$} & \multicolumn{2}{|c|}{ CORRIENTES } & \multirow{2}{*}{ TOTAL } \\
\hline & V & $M$ & V & M & & V & $M$ & MIXTOS & V & M & \\
\hline Encuestas a estudiantes & 74 & 38 & 70 & 54 & 236 & 31 & 33 & - & 23 & 15 & 102 \\
\hline Grupos Focales & 3 & 3 & 3 & 3 & 12 & 2 & 1 & 2 & 2 & 2 & 9 \\
\hline
\end{tabular}

Las dos regiones seleccionadas presentan características socio-productivas y culturales diferenciadas. El Gran Buenos Aires es el territorio en torno a la Ciudad de Buenos Aires que concentra una parte importante de la actividad económica de la Argentina. Más allá que, como en el resto del país, los sectores de Servicios y Comercio son los que tienen mayor peso en la ocupación en la región, se destaca también la Industria manufacturera y la Construcción, con una presencia más importante que en el total del país. El Conurbano Bonaerense no es homogéneo. En la presente investigación se trabajó en la región que comprende los municipios de Quilmes, Berazategui y Florencio Varela, ubicados al sur del Conurbano, donde encontramos bolsones de pobreza y zonas periurbanas, en contraste con barrios de clase media y media alta. Esta zona se destaca por una importante y diversa actividad industrial, con cierto peso de las pequeñas empresas, aunque también se advierte la presencia de medianas y grandes empresas.

La provincia de Corrientes se ubica en la Región NEA (Nordeste) de la República Argentina. Esta región se caracteriza por presentar, históricamente y de manera sostenida, indicadores que la ubican como uno de los territorios con mayores índices de pobreza e indigencia, con un escaso desarrollo económico y con un alto grado de informalidad y precariedad en las ocupaciones. Tiene una economía débil por una conjunción de factores: pocas industrias; bajo nivel de remuneraciones; un empresariado marcadamente tradicional con un fuerte predominio de pymes, con niveles de tecnología reducidos y predominio de agroindustrias y actividades comerciales de baja calificación. El sector de mayor importancia relativa es el de servicios y, entre ellos, se destaca el alto porcentaje de empleo público. La región posee no sólo los indicadores más bajos de actividad y de ocupación del país, sino también algunos vinculados a educación. En términos culturales, algunos rasgos identitarios de la sociedad correntina son el catolicismo, el criollismo y el conservadorismo (Guber, 2001).

\footnotetext{
La EST está constituida por dos ciclos: un Ciclo Básico, de tres años de duración, y común a todas las tecnicaturas, y un Ciclo Superior de cuatro años de duración y orientado a cada una de las especialidades.

8 En la mayoría de los casos -salvo en dos del Conurbano- los grupos estuvieron integrados según género (varones por un lado y mujeres por otro).

9 La investigación completa abarcaba también entrevistas en profundidad a directivos/as y a un grupo de docentes de cada institución, para captar estrategias institucionales y prácticas y expectativas de los/as docentes.
} 


\section{Las elecciones por la Educación Técnico Profesional: motivaciones iniciales y expectativas futuras}

\section{1. Las/los estudiantes de escuelas secundarias técnicas}

Nos preguntamos en este artículo por los motivos de las elecciones de los estudiantes de ETP que alimentan la segregación por género en la modalidad. En la encuesta realizada hemos explorado las razones que llevaron a la elección de una escuela con orientación técnica, encontrando diferencias notorias, vinculadas con el género así como con la región (Tabla II).

Tabla II. Principales motivos por los que eligieron estudiar en una Escuela Técnica

\begin{tabular}{lcccc}
\hline \multirow{2}{*}{ MOTIVO } & \multicolumn{2}{c}{ CONURBANO SUR } & \multicolumn{2}{c}{ CORRIENTES } \\
\cline { 2 - 5 } & VARONES & MUJERES & VARONES & MUJERES \\
\hline Porque quiero seguir una carrera terciaria/universitaria relacionada con la formación técnica & $32 \%$ & $45 \%$ & $17 \%$ & $20 \%$ \\
\hline Porque la formación técnica brinda mayores posibilidades de conseguir un trabajo & $46 \%$ & $59 \%$ & $59 \%$ & $54 \%$ \\
\hline Porque me gusta la formación práctica & $4 \%$ & $16 \%$ & $7 \%$ & $9 \%$ \\
\hline Por tradición familiar & $1 \%$ & $5 \%$ & $6 \%$ & $11 \%$ \\
\hline Porque no había otra opción & $3 \%$ & $5 \%$ & $9 \%$ & $4 \%$ \\
\hline Otro motivo & $14 \%$ & $0 \%$ & $3 \%$ & $2 \%$ \\
\hline & $100 \%$ & $100 \%$ & $100 \%$ & $100 \%$ \\
\hline
\end{tabular}

Fuente: elaboración propia a partir de datos de encuestas aplicadas a estudiantes de Escuelas Secundarias Técnicas.

Para los varones de ambos distritos, la principal motivación se asocia a la idea de las mayores posibilidades que otorga esta modalidad para conseguir un trabajo. Esta tendencia, sin embargo, es más pronunciada en los jóvenes de Corrientes que en los del Conurbano Bonaerense. En segundo lugar, aparece la relación entre la elección de la modalidad con la intención futura de realizar una carrera terciaria/universitaria vinculada con la formación técnica. También aquí se advierte una diferencia entre ambos distritos: es notoriamente menor el porcentaje de los varones correntinos que optaron por esta respuesta.

En el grupo de las mujeres, también hay algunas variaciones significativas. Mientras que el 45\% de las jóvenes del Conurbano Bonaerense mencionó como principal motivo el vínculo de la escuela técnica con la formación futura en el nivel superior, esto desciende en 25 puntos porcentuales en las jóvenes de Corrientes. Para las jóvenes correntinas, en cambio, el principal móvil está asociado al interés y la necesidad de obtener un trabajo futuro (54\%).

Advertimos en estos resultados el peso de los distintos contextos regionales, que opaca las diferencias de género, más claras en el Conurbano Sur. Hemos descripto ya el escenario de escaso desarrollo económico y debilidad del mercado laboral correntino. En este marco, los/as jóvenes priorizan el acceso temprano al empleo, a fin de generar ingresos, postergando sus proyectos formativos. Este tipo de decisiones ha quedado de manifiesto en los grupos focales.

Si bien en el cuadro anterior la familia no parece tener gran peso en la elección de la modalidad técnica, otro ítem de la encuesta muestra que los familiares constituyen el canal principal a través del que los/as estudiantes se informaron sobre la oferta de la escuela, seguidos por los amigos y conocidos. Al igual que en otros estudios realizados en Latinoamérica (OIT, 2014; Perez Moreno, 2012) un 
hecho bastante frecuente es que los/as estudiantes tienen hermanos/as cursando y/o egresados/as de estas mismas escuelas y que alguno de sus referentes adultos también lo sean (o bien hayan asistido a alguna otra escuela técnica).

En cuanto a las razones de elección de las especialidades las respuestas de los varones de ambas jurisdicciones son bastante similares, indicando en primer término el «gusto» por el tipo de actividad (47\% Conurbano Sur, 4\% Corrientes) -vale decir, motivaciones expresivas- y, luego, la creencia de que les ayudará a conseguir un trabajo (26 y 30\% respectivamente). En las respuestas de las mujeres, en cambio, existen algunas variaciones por región: en las estudiantes del Conurbano Sur el $46 \%$ indicó en primer lugar «porque me prepara para una carrera que quiero seguir», en tanto que solo el 15\% de las jóvenes correntinas señaló esta opción, confirmando en cambio su orientación hacia el empleo (30\%, contra 16\% Conurbano Sur). A su vez, las motivaciones expresivas (el «gusto» por la especialidad) tienen un peso importante en las mujeres de ambas jurisdicciones (44\% Corrientes y 30\% Conurbano), al igual que ocurre con sus pares varones. De los grupos focales se desprende que en este «gusto» tienen un peso importante ciertas figuras familiares que aparecen como modelo.

Otro aspecto que interviene en la elección de la especialidad son las estrategias de los centros educativos. Si bien directivos y docentes sostienen en las entrevistas que las escuelas no tienen una política institucional explícita en relación al género, alrededor de un 30\% de las estudiantes de ambas regiones consideran haber recibido orientaciones diferenciadas para varones y mujeres en el ingreso, en relación a la especialidad (contra un $13 \%$ de los varones del Conurbano y un $26 \%$ de los correntinos). Esto apareció corroborado en uno de los grupos focales de Corrientes, donde identificamos la existencia de prácticas en las que los directivos orientan, seleccionan y/o asignan los cupos en las especialidades, desde una visión que reproduce la división sexual del trabajo.

«El rector bace una reunión con todos los cursos cuando bay que elegir orientación. Lo primero que dijo fue que las mujeres no podian ir a electricidad o mecánica.

(...) Cuando te querés inscribir te dicen que no hay lugar. Ponen excusas para sacarte de lado. Yo quería elegir electricidad, y te dicen que hay cupos limitados, solo dos mujeres. Se inscribian las que se inscribian, pero seleccionaban dos». (Grupo focal de mujeres de Administración y Gestión, Corrientes).

Por otra parte, las normas institucionales no siempre operan a través de políticas y prácticas explícitas como la antes mencionada, sino también a través de climas y culturas organizacionales, los cuales suelen estar atravesados por estereotipos de género (Subirats, 2016). Un ejemplo son las visiones que se construyen sobre las especialidades:

«Estudiante 1: Acá [en Química] hay más mujeres que varones, antes [a esta escuela técnica] venian solo varones, y también como que ven que electro era para varones. (...)

Moderador: ¿Cuáles son las frases que circulan sobre las especialidades? 


\section{Estudiante 3: Que quimica es de gay.}

Estudiante 2: Por eso hay más mujeres que varones». (Grupo focal de varones de Química, Conurbano Sur).

En relación con las expectativas para el futuro inmediato, luego de terminar el nivel, las respuestas son bastante coincidentes: los/as jóvenes en ambas jurisdicciones se plantean una combinación de estudio y trabajo. Muy pocos/as estudiantes manifiestan que no seguirán una carrera universitaria o terciaria: por priorizar el trabajo, por no saber qué estudiar o bien por proyectarse en algún oficio, apelando para ello a algún curso de FP. Esta última tendencia aparece de manera más pronunciada en Corrientes, especialmente en los/as estudiantes de una institución ubicada en una localidad del interior de la provincia, más alejada de la variedad de ofertas universitarias y terciarias que ofrece la capital, reflejando las desigualdades territoriales vigentes en Argentina.

Por otra parte, también son muy pocos/as los/as que se inclinan solo por el estudio, apostando a que su familia podría seguir sosteniéndolos/as durante su carrera universitaria -o por lo menos, en sus comienzos-. Por el contrario, la opción por combinar ambas actividades es considerada como una necesidad, frente a las dificultades económicas familiares, pero también como una responsabilidad de aligerar la carga familiar y un interés por lograr cierta independencia propia, pudiendo solventar sus gastos.

En relación con las expectativas de inserción laboral y, más específicamente sobre los tipos de trabajos en los que creen que podrían desempeñarse cuando terminen la secundaria también encontramos variaciones importantes entre varones y mujeres así como entre regiones. Los estudiantes varones en ambas jurisdicciones mayoritariamente consideran que pueden conseguir un trabajo vinculado directamente con la especialidad de formación, aunque las expectativas positivas son claramente más elevadas en los del Conurbano Sur que en los de Corrientes (Tabla III). Aunque en un porcentaje un poco menor, las expectativas de las estudiantes mujeres del Conurbano Bonaerense también son muy positivas.

Tabla III. Tipo de trabajo en el que creen que podrían desempeñarse cuando terminen la secundaria

\begin{tabular}{lcccc}
\hline \multirow{2}{*}{ TIPO DE TRABAJO } & \multicolumn{2}{c}{ CONURBANO BONAERENSE } & \multicolumn{2}{c}{ CORRIENTES } \\
\cline { 2 - 5 } & VARONES & MUJERES & VARONES & MUJERES \\
\hline En un trabajo directamente relacionado con la especialidad técnica & $57 \%$ & $46 \%$ & $45 \%$ & $29 \%$ \\
\hline En otro trabajo en el que aplique alguno de los conocimientos aprendidos en la especialidad técnica & $31 \%$ & $46 \%$ & $38 \%$ & $44 \%$ \\
\hline En cualquier otro trabajo para un egresado del nivel secundario & $12 \%$ & $8 \%$ & $17 \%$ & $27 \%$ \\
\hline & $100 \%$ & $100 \%$ & $100 \%$ & $100 \%$ \\
\hline
\end{tabular}

Fuente: elaboración propia a partir de datos de encuestas aplicadas a estudiantes de Escuelas Secundarias Técnicas.

Justamente, un aspecto interesante captado en los grupos focales, que contrasta con otras investigaciones realizadas con estudiantes de nivel secundario del Conurbano Bonaerense, es la confianza que manifiesta la mayoría de los/as jóvenes - tanto varones como mujeres- en conseguir trabajo. Esto aparece directamente ligado con la especialidad técnica estudiada: la convicción de los/as participantes 
en los grupos focales es que tienen un saber específico, técnico, que es demandado en el mercado de trabajo. Una segunda percepción es que la escuela ha desarrollado en ellos competencias personales y socio-relacionales que son fundamentales para una inserción laboral exitosa: la disciplina, la responsabilidad, el compromiso con la tarea, la capacidad de trabajo en equipo, de expresar las propias ideas y saberes. Esto aparece vinculado al régimen académico de la escuela secundaria técnica que, a diferencia de otras modalidades en la escuela pública, requiere largas horas de cursada, en doble turno.

En las respuestas de las estudiantes mujeres de Corrientes, en cambio, encontramos expectativas mucho menos positivas. La mayoría de ellas considera que podrán acceder a alguna ocupación pero solo medianamente relacionada con la especialidad que cursaron. A su vez quienes expresan esta visión son las que cursan carreras vinculadas con Administración y Gestión (es decir una orientación tradicionalmente asociada a lo femenino).

Las desigualdades entre varones y mujeres se hacen más claras a la hora de considerar las expectativas educativas -vale decir, en su proyección profesional a futuro-, que hemos explorado a través de los grupos focales. Como hemos señalado, la mayoría de los y las estudiantes se plantean continuar una carrera universitaria o terciaria. No obstante, en Informática, Construcciones y Madera y Mueble -tres especialidades donde las mujeres son minoría-, las carreras elegidas son marcadamente diferentes: mientras la gran mayoría de los varones (sobre todo los del Conurbano Sur) se proyectan estudiando carreras directamente ligadas a la especialidad, con preponderancia de las ingenierías, las mujeres presentan una diversidad mucho mayor, eligiendo generalmente profesiones no ligadas con la especialidad técnica.

Por último identificamos también otro tipo de desigualdades, vinculadas a lo territorial, que trascienden las diferencias de género e inciden fuertemente en las expectativas educativas y proyecciones inmediatas futuras. Así, por ejemplo muchos estudiantes varones de Corrientes, si bien proyectan continuar sus estudios, prefieren hacerlo en carreras más cortas, con una salida laboral más rápida y en ocasiones totalmente desvinculadas de las especialidades que cursaron (entre ellas muchos casos al empleo público en la docencia o en alguna fuerza de seguridad: policía, fuerzas armadas, etc.).

\subsection{Las/los estudiantes de los Centros de Formación Profesional}

La FP aparece en la percepción de los/as estudiantes como un nivel directamente relacionado con la mejora de las oportunidades laborales. El principal motivo por el que, tanto varones como mujeres de ambas regiones, eligieron estudiar en este tipo de instituciones es «para tener un mayor acceso al mundo laboral» (Tabla IV). Aunque esta es una respuesta común y generalizada, en el caso de las mujeres de Corrientes se advierte también cierto peso de motivaciones expresivas. 


\section{Tabla IV. Principales motivos por los que eligieron estudiar en un Centro de Formación Profesional}

\begin{tabular}{|c|c|c|c|c|}
\hline \multirow{2}{*}{ MOTIVO } & \multicolumn{2}{|c|}{ CONURBANO BONAERENSE } & \multicolumn{2}{|c|}{ CORRIENTES } \\
\hline & VARONES & MUJERES & VARONES & MUJERES \\
\hline Para tener un mayor acceso al mundo laboral & $71 \%$ & $76 \%$ & $61 \%$ & $40 \%$ \\
\hline Porque me gusta la formación práctica & $16 \%$ & $6 \%$ & $17 \%$ & $27 \%$ \\
\hline Por sugerencia de un amigo o familiar & $3 \%$ & $9 \%$ & $4 \%$ & $13 \%$ \\
\hline \multirow[t]{2}{*}{ Otro motivo } & $10 \%$ & $9 \%$ & $17 \%$ & $20 \%$ \\
\hline & $100 \%$ & $100 \%$ & $100 \%$ & $100 \%$ \\
\hline
\end{tabular}

Fuente: elaboración propia a partir de datos de encuestas aplicadas a estudiantes de cursos de Formación Profesional.

Algo similar ocurre en torno a los principales motivos de la elección de los cursos que se encontraban realizando. En términos generales, en ambas jurisdicciones, las respuestas se distribuyen mayoritariamente en tres principales tipos de motivaciones, dos instrumentales, ligadas a lo laboral y una expresiva: porque consideran que el curso les puede ayudar a conseguir un trabajo; porque entienden que le servirá, como capacitación, en su actual trabajo, y porque les gusta la especialidad.

Los grupos focales muestran que el peso otorgado a cada uno de estos motivos varía en función a la situación laboral en la que se encuentran. En efecto, a diferencia de los/as estudiantes de EST, los/as de FP están insertos en el mercado laboral (ya sea a tiempo completo o de manera eventual) ${ }^{10}$. Para los desocupados/as, la certificación que otorgan estas instituciones constituye un capital que los posiciona mejor al momento de la búsqueda de un empleo y, al mismo tiempo, los saberes aprendidos vinculados a ciertos oficios brindan la posibilidad de iniciar un trabajo de manera independiente como cuentapropistas. Para quienes se encuentran ocupados, los saberes y las certificaciones contribuyen a que puedan sostener y/o mejorar su situación laboral.

En los varones de ambas jurisdicciones las tres motivaciones antes mencionadas se distribuyen de manera bastante proporcional. En las mujeres, en cambio, se registran algunas diferencias. Mientras que para la mayoría de las del Conurbano Bonaerense la principal motivación es el aporte que puede tener el curso para conseguir un trabajo, en las mujeres correntinas hay un mayor grado de dispersión en torno a sus motivaciones. Algunos ejemplos de este tipo encontramos en las respuestas de las asistentes a los cursos de reparación de PC y de diseño y construcción de muebles, quienes manifestaron que lo que las motivó a inscribirse era poder aprender algo que no sabían, que les gusta («que siempre les interesó») o que puede ser de utilidad dentro de sus hogares (para poder hacerlo ellas, sin gastar dinero) y, eventualmente, ofrecer como un servicio a algunos/as conocidos.

En los grupos focales encontramos, en línea con lo que señalan otros estudios de Argentina (Millenaar y Jacinto, 2015), que para muchas mujeres, los cursos de formación profesional constituyen también un espacio de socialización, de encuentro con otras/os y un tiempo para sí mismas que les permite alejarse, por momentos, de sus roles de ama de casa y de las tareas domésticas. Esta motivación relacional la encontramos también en algunos varones participantes de uno de los grupos focales del Conurbano correspondiente a un curso de la familia de la Construcción: se trataba de vecinos del

10 Mientras el 84\% de los estudiantes varones de FP del Conurbano Sur y el 78\% de los de Corrientes realiza actividades laborales extradomésticas -a tiempo completo o eventuales-, sólo lo hacen el 28\% y el 37\% respectivamente de los de EST (y son ínfimos los porcentajes de los que trabajan a tiempo completo). Entre las mujeres estas cifras bajan, pero es clara la diferencia: $61 \%$ de estudiantes de FP del Conurbano Sur y $53 \%$ de Corrientes, contra un $24 \%$ de estudiantes de EST en ambas jurisdicciones (también mayormente en trabajos eventuales). 
CFP, algunos jubilados o en edades próximas a la jubilación, que veían en el curso no solo una posibilidad de poder desarrollar un emprendimiento propio luego del retiro, sino un espacio de sociabilidad.

Finalmente en relación con las expectativas de inserción laboral y sobre los tipos de trabajos que creen que podrían conseguir cuando terminen el curso observamos también variaciones según género y las características de los mercados de trabajo en cada una de las jurisdicciones (Tabla V).

\section{Tabla V. Tipo de trabajo en el que creen que podrían desempeñarse cuando terminen la formación profesional}

\begin{tabular}{|c|c|c|c|c|}
\hline \multirow{2}{*}{ TIPO DE TRABAJO } & \multicolumn{2}{|c|}{ CONURBANO BONAERENSE } & \multicolumn{2}{|c|}{ CORRIENTES } \\
\hline & VARONES & MUJERES & VARONES & MUJERES \\
\hline En un trabajo directamente relacionado con la especialidad técnica & $45 \%$ & $27 \%$ & $30 \%$ & $27 \%$ \\
\hline En otro trabajo en el que aplique alguno de los conocimientos aprendidos en la especialidad técnica & $35 \%$ & $55 \%$ & $61 \%$ & $60 \%$ \\
\hline \multirow[t]{2}{*}{ En cualquier otro trabajo no relacionado con la especialidad técnica } & $19 \%$ & $18 \%$ & $9 \%$ & $13 \%$ \\
\hline & $100 \%$ & $100 \%$ & $100 \%$ & $100 \%$ \\
\hline
\end{tabular}

Fuente: elaboración propia a partir de datos de encuestas aplicadas a estudiantes de cursos de Formación Profesional.

Mientras que los varones del Conurbano Sur consideran en mayor porcentaje que pueden conseguir un trabajo vinculado directamente con la especialidad de formación, los correntinos consideran que lo harán en trabajos medianamente vinculados con la formación realizada. Las visiones de las mujeres, en ambas jurisdicciones, son claramente menos positivas: solo 3 de cada 10 considera que podría conseguir y/o generar un trabajo directamente vinculado con el con la formación realizada. No obstante, sumando ambas opciones, advertimos que la gran mayoría de los/as estudiantes, en ambas jurisdicciones, considera que la FP genera una diferencia, en tanto los conocimientos adquiridos pueden ser movilizados en el mercado de trabajo, más directa o más indirectamente.

Concluyendo este apartado, advertimos que en la elección de la ETP tienden a primar las motivaciones instrumentales: desde la perspectiva de los/as estudiantes, es una modalidad que favorece el acceso al empleo. En el caso de EST, y con notables diferencias por región y por género, aparece también su conexión con los estudios universitarios. Estas motivaciones también intervienen en la elección de la especialidad, pero acá para algunos/as estudiantes cobran importancia las motivaciones expresivas, nuevamente con diferencias por región, género y nivel de ETP. Las diferencias regionales y entre varones y mujeres también se hacen explícitas al analizar las expectativas de inserción en el mercado laboral. Esto nos lleva a preguntarnos, en relación con la discusión teórica, ¿en qué medida persisten en los estudiantes de ETP de ambos niveles estereotipos en relación a la división sexual del trabajo? Esta pregunta adquiere relevancia por el proceso acelerado de cambio en los discursos públicos en relación al género que se advierte en Argentina. 


\section{Estereotipos de género sobre la división sexual del trabajo: diferencias regionales} y generacionales

\section{1. Las/los estudiantes de EST}

En nuestra investigación hemos explorado en la parte cuantitativa, a través de escalas de opinión, la presencia o no de estereotipos en torno tanto al trabajo extra-doméstico como doméstico -en el entendimiento que es en la relación recíproca de estas esferas que se reproducen o modifican las desigualdades de género-. En lo que respecta a los primeros, hemos visto que estos estereotipos se basan en dos principios organizadores: un principio de separación y un principio de jerarquización.

La persistencia del principio de separación se manifiesta al examinar las respuestas a dos ítems: «Algunos trabajos deben ser solo para varones» y «Algunos trabajos deben ser solo para mujeres». Como se observa en la Tabla VI, entre los varones los porcentajes de rechazo a estas afirmaciones estereotipadas son bajos: 35 y $40 \%$ respectivamente en el Conurbano Sur; 26 y $31 \%$ en Corrientes. La diferencia con las mujeres resulta clara en ambas regiones, pero es mucho más marcada en el Conurbano Sur: 71 y $76 \%$ de las estudiantes del Conurbano rechazan cada una de estas frases estereotipadas; contra sólo $46 \%$ y $41 \%$ de las estudiantes correntinas, que en este sentido resultan más cercanas en sus opiniones a los varones del Conurbano Sur.

\section{Tabla VI. Percepciones no estereotipadas sobre los roles de varonesy mujeres en la división sexual del trabajo. (\% de respuestas en desacuerdo o muy en desacuerdo con las afirmaciones)}

\begin{tabular}{|c|c|c|c|c|}
\hline \multirow{2}{*}{ AFIRMACIONES } & \multicolumn{2}{|c|}{ CONURBANO BONAERENSE } & \multicolumn{2}{|c|}{ CORRIENTES } \\
\hline & VARONES & MUJERES & VARONES & MUJERES \\
\hline «Los varones son mejores que las mujeres para desempeñarse como jefes» & $50 \%$ & $89 \%$ & $29 \%$ & $69 \%$ \\
\hline «Las mujeres son mejores que los varones para desempeñarse en trabajos en los que tienen que recibir órdenes» & $53 \%$ & $76 \%$ & $33 \%$ & $30 \%$ \\
\hline «Algunos trabajos deben ser solo para varones» & $35 \%$ & $71 \%$ & $26 \%$ & $46 \%$ \\
\hline «Algunos trabajos deben ser solo para mujeres» & $40 \%$ & $76 \%$ & $31 \%$ & $41 \%$ \\
\hline «Las tareas del hogar son principalmente responsabilidad de las mujeres» & $62 \%$ & $92 \%$ & $49 \%$ & $59 \%$ \\
\hline (\% de respuesta en acuerdo o muy de acuerdo con las afirmaciones) & - & - & - & - \\
\hline «El cuidado y la educación de los hijos deben ser compartidos entre el padre y la madre» & $86 \%$ & $97 \%$ & $97 \%$ & $94 \%$ \\
\hline
\end{tabular}

Fuente: elaboración propia a partir de datos de encuestas aplicadas a estudiantes de Escuelas Secundarias Técnicas.

Este panorama se ve corroborado al examinar las percepciones de los/as estudiantes sobre distintas ocupaciones listadas ${ }^{11}$. Si bien hay un conjunto de ocupaciones sobre las cuales altos porcentajes de encuestados/as (superior al $75 \%$ en todos los casos) consideran que pueden ser desempeñadas bien tanto por varones como por mujeres ${ }^{12}$; hay otros dos grupos (uno de ocupaciones relacionadas con el trabajo manual, a menudo de baja calificación ${ }^{13}$; y otro de ocupaciones de carácter técnico) $)^{14}$, en los que no solo descienden los porcentajes de percepciones no estereotipadas, sino que las respuestas presentan contrastes por región y por género.

\footnotetext{
11 En este caso, la encuesta preguntaba: «En tu opinión, ¿quién podría desempeñar mejor los siguientes trabajos?», y presentaba un listado de ocupaciones -relacionadas con las familias profesionales trabajadas en cada región-, dando como opción de respuesta en cada caso: Varón, Mujer, Ambos.

12 Tal es el caso de: Asistente de informática, Administrativo/a, Gerente, Guía de turismo, Cocinero/a, Técnico/a de laboratorio.

13 Albañil, Carpintero/a, Forestador/a, Operador/a de sierras, Obrero/a rural, Operador/a técnico/a de campo (boca pozo petróleo).

14 Técnico en mantenimiento eléctrico, Técnico en mantenimiento mecánico.
} 


\section{Tabla VII. Percepciones no estereotipadas sobre el desempeño de ocupaciones (\% de respuestas «ambos»).}

\begin{tabular}{|c|c|c|c|c|}
\hline \multirow{2}{*}{ OCUPACIÓN/PROFESIÓN/TRABAJO } & \multicolumn{2}{|c|}{ CONURBANO BONAERENSE } & \multicolumn{2}{|c|}{ CORRIENTES } \\
\hline & VARONES & MUJERES & VARONES & MUJERES \\
\hline Reparador/a de PC & $88 \%$ & $95 \%$ & $69 \%$ & $67 \%$ \\
\hline Programador/a /Desarrollador/a de Software & $93 \%$ & $95 \%$ & $69 \%$ & $77 \%$ \\
\hline Asistente de informática & $91 \%$ & $92 \%$ & $79 \%$ & $78 \%$ \\
\hline Carpintero/a & $59 \%$ & $69 \%$ & $50 \%$ & $48 \%$ \\
\hline Forestador/a & $62 \%$ & $61 \%$ & $37 \%$ & $39 \%$ \\
\hline Albañil & $38 \%$ & $50 \%$ & $30 \%$ & $19 \%$ \\
\hline Operador/a de sierras & $57 \%$ & $59 \%$ & $50 \%$ & $28 \%$ \\
\hline Administrativo/a & $82 \%$ & $86 \%$ & $77 \%$ & $77 \%$ \\
\hline Gerente & $89 \%$ & $89 \%$ & $86 \%$ & $94 \%$ \\
\hline Guía de turismo & $85 \%$ & $92 \%$ & $77 \%$ & $83 \%$ \\
\hline Cocinero/a & $84 \%$ & $95 \%$ & $80 \%$ & $85 \%$ \\
\hline Técnico/a de laboratorio & $94 \%$ & $89 \%$ & $86 \%$ & $91 \%$ \\
\hline Obrero/a rural & $58 \%$ & $78 \%$ & $46 \%$ & $39 \%$ \\
\hline Operador/a de maquinaria & $70 \%$ & $71 \%$ & $47 \%$ & $39 \%$ \\
\hline Podador/a & $74 \%$ & $65 \%$ & $61 \%$ & $57 \%$ \\
\hline Operador/a técnico/a de campo (boca pozo petróleo) & $58 \%$ & $76 \%$ & $40 \%$ & $39 \%$ \\
\hline Técnico/a en mantenimiento eléctrico & $78 \%$ & $84 \%$ & $57 \%$ & $70 \%$ \\
\hline Técnico/a en mantenimiento mecánico & $73 \%$ & $79 \%$ & $46 \%$ & $57 \%$ \\
\hline
\end{tabular}

Fuente: elaboración propia a partir de datos de encuestas aplicadas a estudiantes de Escuelas Secundarias Técnicas.

Resulta claro del análisis del cuadro anterior que las ocupaciones consideradas «típicamente masculinas» por un porcentaje importante de estudiantes son aquellas ligadas a la fuerza física y a la resistencia. Pero advertimos acá diferencias importantes por región: el porcentaje de percepciones no estereotipadas es siempre mayor en el Conurbano Sur que en Corrientes. El género profundiza estas divergencias: mientras que entre los varones las diferencias son menores, entre las mujeres se advierte una amplia brecha -siempre superior a los 20 puntos porcentuales, pero a veces llegando incluso a más de 35-. Vale decir que son las estudiantes correntinas las que tienden a considerar en mayor medida que este tipo de ocupaciones que requieren esfuerzo físico no son para mujeres, en tanto son las estudiantes del Conurbano Sur las que ponen más en cuestión esta perspectiva tradicional.

Esto cambia al considerar las ocupaciones que requieren el manejo de ciertas competencias técnicas: si bien se sigue conservando la diferencia entre regiones, acá en el caso de Corrientes es mayor el porcentaje de mujeres, en comparación con los varones, que considera que este tipo de trabajo puede ser desempeñado igualmente bien por ambos géneros.

Consideramos que este análisis resulta interesante, porque relaciona la persistencia del principio de separación con estereotipos binarios arraigados que, como mencionamos en el apartado teórico, asignan atributos y capacidades diferenciales a varones y mujeres - en este caso, fuerza física, por un lado, y un saber-hacer técnico, en el último grupo--. Volveremos sobre este tema un poco más adelante.

Pasando ahora al principio de jerarquización, este fue abordado a partir de dos ítems de la escala de opinión: «Los varones son mejores que las mujeres para desempeñarse como jefe» y «Las mujeres son 
mejores que los varones para desempeñarse en trabajos en los que tienen que recibir órdenes». Acá advertimos nuevamente divergencias entre regiones y por género. Mientras un $89 \%$ de las mujeres del Conurbano Sur rechazaron la primera afirmación y el $76 \%$ la segunda, en el otro extremo, solo el 29\% y el $33 \%$ de los varones correntinos, respectivamente, estuvieron en desacuerdo con ellas. Los varones del Conurbano Sur se ubican en una posición intermedia, aunque con diferencias muy significativas con las mujeres de la misma región (más del 20\%). Un caso paradójico es el de las mujeres correntinas, que si bien rechazan la primacía de los varones en las jefaturas, muestran en su respuesta una gran vigencia en esta región de la idea de la mujer como subordinada, como capaz de acatar órdenes.

Por último, dos ítems medían estereotipos en relación con la división del trabajo doméstico: «El cuidado y la educación de los hijos deben ser compartidos entre el padre y la madre» y «Las tareas del hogar son principalmente responsabilidad de las mujeres». El contraste entre las respuestas a estos dos ítems es importante. Si en el primer caso la gran mayoría de los entrevistados/as acuerda con esta afirmación no estereotipada, en la segunda afirmación se encuentran notables diferencias entre regiones y por género: nuevamente, los porcentajes de percepciones no estereotipadas por género son mayores en el Conurbano que en Corrientes, pero a la vez en cada jurisdicción las mujeres tienden a rechazar el estereotipo mucho más que los varones. Esto coincide con lo que indica la bibliografía en relación a que los cambios en el involucramiento de los varones en la esfera doméstica han sido importantes en lo que respecta a la crianza y cuidado de los hijos, pero siguen siendo lentos en la participación de los varones en tareas vinculadas con la limpieza y el funcionamiento del hogar (Wainerman, 2005).

Para completar este punto, podemos poner en relación estos resultados con las representaciones sobre las desigualdades de género en el mercado laboral expresadas por los/as estudiantes en los grupos focales. La contracara de los estereotipos arraigados es la invisibilización o la naturalización de tales desigualdades. En efecto, en muchos grupos focales, la primera reacción ante la pregunta por las oportunidades de varones y mujeres en el mercado de trabajo asociado a la especialidad estudiada fue sostener la igualdad de oportunidades, desestimando a menudo las diferencias como algo del pasado, que ya había sido superado. Particularmente entre los varones, esta apreciación es fundamentada con ejemplos de casos particulares de mujeres empleadas en la especialidad.

«Estudiante 1: Y yo tengo una prima que está estudiando Ingeniería en Sistemas en el Chaco y este año se recibe y ella terminó acá en el 2004.

Estudiante 2: Yo creo que las mujeres y hombres tienen las mismas posibilidades de conseguir trabajo en informática». (Grupo focal de varones de Informática, Corrientes).

Al repreguntar o mencionar ejemplos específicos, sin embargo, comienzan a mencionarse desigualdades. Por un lado, se reconocen prácticas discriminatorias de los/as empleadores/as, ligadas a la condición de género - por ejemplo, la resistencia a contratar mujeres, por la creencia de que las dificultades de conciliación de la vida familiar y laboral puede atentar contra su productividad-. Por el otro, se naturalizan diferencias, fundamentándolas en los estereotipos acerca de atributos y capacidades diversas de varones y mujeres que ya hemos visto en las encuestas. Una vez más, los varones aparecen relacionados con la fuerza y las mujeres con la debilidad. Pero también se señalan atributos positivos 
de las mujeres: la imaginación, el orden, las capacidades expresivas... la matriz de oposiciones binarias sobre la cual opera la construcción social de la diferencia sexual se hace evidente. Asimismo, salen a la luz estereotipos que tienen que ver con las jerarquías y el poder, asociándose a la mujer a la obediencia y a la subordinación.

\begin{abstract}
«Estudiante 1: En la obra se ven más hombres, en la parte administrativa sí hay mujeres, pero qué se yo... están haciendo un edificio y la mayoría son todos albañiles. Muy raro ver a una chica o a una mujer abi, haciendo un pastón, o poniendo ladrillos. En diseño sí... porque bay veces que las mujeres tienen más imaginación para hacer esas cosas. (...)
\end{abstract}

Moderador: ¿Y quépiensan ustedes de una mujer dirigiendo una obra, dirigiendo a varones?

\begin{abstract}
Estudiante 2: Es demasiado raro. ¿Pero ustedes que es lo que quieren establecer? (Ahi se produce una superposición de voces; momento de discusión) No es machista, pero es muy raro. Es demasiado raro. Que una mujer dirija muchos hombres... es demasiado raro». (Grupo focal de varones de Construcciones, Conurbano Sur).
\end{abstract}

Sin embargo, esta situación de invisibilización y naturalización de las desigualdades de género en el mercado laboral no es unánime en todos los grupos focales. Particularmente en las especialidades con mayor presencia de mujeres se advierten perspectivas más críticas. Tal es el caso de Química, donde las estudiantes problematizan y confrontan las experiencias de discriminación en el empleo industrial que ellas mismas han experimentado en las prácticas profesionalizantes ${ }^{15}$. En Corrientes, las estudiantes de Administración y Gestión no solo son más conscientes que sus pares varones de las desigualdades de género en el acceso al mercado de trabajo, sino que también ponen en cuestión situaciones de subordinación de las mujeres en el ámbito de las relaciones familiares y de pareja. Se refieren así a la autoridad de la figura paterna y a cierta mirada «machista» de los varones novios de sus amigas, sobre todo en relación con los roles domésticos tradicionales y la maternidad como un proyecto al que necesariamente las mujeres deben concretar, en algún momento. Aspectos que reflejan los rasgos tradicionales de la cultura correntina ${ }^{16}$.

En el caso de Química, la posibilidad de la crítica aparece específicamente potenciada por la reflexión que sobre la temática impulsan algunos/as profesores, particularmente profesoras mujeres. Estas últimas también resultan, en el discurso de las estudiantes, figuras de identificación que ayudan a romper con estereotipos. De este modo, advertimos en ciertas prácticas institucionales y de los docentes una capacidad para poner en cuestión desigualdades de género, tal como muestran las investigaciones de Archer y otros (2020). Paradójicamente, en esta investigación hemos encontrado esto sobre todo en especialidades con mayor presencia de mujeres. Se trata, no obstante, de un tema a profundizar.

15 Estas prácticas, de carácter obligatorio, son espacios formativos que buscan acercar a los/as estudiantes a situaciones reales del mercado laboral. En tal sentido, se prevén prácticas externas en empresas, organismos gubernamentales y organizaciones sociales, a través de convenios con las escuelas. Pero como no hay suficientes lugares, también se realizan prácticas en la propia escuela, en proyectos internos o en proyectos de extensión que buscan responder a demandas de la comunidad. La experiencia de estas estudiantes es que las empresas en las que se realizan prácticas externas no reciben a estudiantes mujeres.

16 En un grupo focal de varones se reflejaba la vigencia de estos estereotipos, en tanto ellos señalaban que sus compañeras «por el simple hecho de ser mujer» no tienen que trabajar y pueden orientarse más al estudio. («Tal vez piensan tener un novio que las mantenga», sostenía uno de los estudiantes). Se advierte, entonces, la vigencia del estereotipo de varón proveedor y de la mujer confinada al hogar que las estudiantes mujeres denuncian. 


\subsection{Los/as estudiantes de FP}

El análisis cuantitativo de estereotipos de género entre los/as estudiantes de FP presenta convergencias pero también diferencias notables con el de los/as estudiantes de EST. En lo que respecta a los estereotipos ligados a la segregación ocupacional por género, en la Tabla VIII, se advierten porcentajes bastante similares de rechazo entre varones y mujeres de Corrientes y mujeres del Conurbano Sur; en cambio la brecha es importante con los varones del Conurbano: solo el 23\% se manifestó en desacuerdo con la afirmación «Algunos trabajos deben ser solo para varones» y el 26\% expresó su desacuerdo con «Algunos trabajos deben ser solo para mujeres». Vale decir, también entre los/as estudiantes de FP se advierte la persistencia del principio de separación, pero las diferencias entre regiones ha cambiado de dirección: el mayor porcentaje de percepciones estereotipadas se encuentra entre los varones del Conurbano Sur y las mujeres de esta región ya no se distinguen, como en el caso de las estudiantes de nivel secundario, por su alto rechazo a dichos estereotipos.

\section{Tabla VI. Percepciones no estereotipadas sobre los roles de varonesy mujeres en la división sexual del trabajo. (\% de respuestas en desacuerdo o muy en desacuerdo con las afirmaciones)}

\begin{tabular}{|c|c|c|c|c|}
\hline \multirow{2}{*}{ AFIRMACIONES } & \multicolumn{2}{|c|}{ CONURBANO BONAERENSE } & \multicolumn{2}{|c|}{ CORRIENTES } \\
\hline & VARONES & MUJERES & VARONES & MUJERES \\
\hline «Los varones son mejores que las mujeres para desempeñarse como jefes» & $26 \%$ & $58 \%$ & $52 \%$ & $67 \%$ \\
\hline «Las mujeres son mejores que los varones para desempeñarse en trabajos en los que tienen que recibir órdenes» & $26 \%$ & $61 \%$ & $39 \%$ & $67 \%$ \\
\hline «Algunos trabajos deben ser solo para varones» & $23 \%$ & $45 \%$ & $43 \%$ & $47 \%$ \\
\hline «Algunos trabajos deben ser solo para mujeres» & $26 \%$ & $38 \%$ & $48 \%$ & $40 \%$ \\
\hline «Las tareas del hogar son principalmente responsabilidad de las mujeres» & $52 \%$ & $73 \%$ & $61 \%$ & $80 \%$ \\
\hline (\% de respuesta en acuerdo o muy de acuerdo con las afirmaciones) & - & - & - & - \\
\hline «El cuidado y la educación de los hijos deben ser compartidos entre el padre y la madre» & $94 \%$ & $97 \%$ & $96 \%$ & $93 \%$ \\
\hline «Lo importante en el trabajo es la capacidad, no importa ser varón o mujer» & $77 \%$ & $91 \%$ & $83 \%$ & $100 \%$ \\
\hline
\end{tabular}

Fuente: elaboración propia a partir de datos de encuestas aplicadas a estudiantes de Formación Profesional.

El análisis comparativo de las percepciones sobre distintas ocupaciones no resulta tan claro en FP como en EST. Sigue habiendo un conjunto de ocupaciones en relación a las cuales altos porcentajes de encuestados/as sostienen que pueden ser desempeñadas bien tanto por varones como por mujeres, y son más o menos las mismas que en el caso de los/as estudiantes de EST ${ }^{17}$.

\section{Tabla IX. Percepciones no estereotipadas sobre el desempeño de ocupaciones (\% de respuestas «ambos»).}

\begin{tabular}{lcccc}
\hline \multirow{2}{*}{ OCUPACIÓN/PROFESIÓN/TRABAJO } & \multicolumn{2}{c}{ CONURBANO BONAERENSE } & \multicolumn{2}{c}{ CORRIENTES } \\
\cline { 2 - 4 } & VARONES & MUJERES & VARONES & MUJERES \\
\hline Reparador/a de PC & $84 \%$ & $65 \%$ & $78 \%$ & $80 \%$ \\
\hline Programador/a /Desarrollador/a de Software & $81 \%$ & $76 \%$ & $87 \%$ & $80 \%$ \\
\hline Asistente de informática & $74 \%$ & $88 \%$ & $83 \%$ & $93 \%$ \\
\hline Carpintero/a & $65 \%$ & $64 \%$ & $61 \%$ & $73 \%$ \\
\hline
\end{tabular}

17 Asistente de informática, Administrativo/a, Gerente, Guía de turismo, Cocinero/a, Técnico/a de laboratorio, a las que se agregan Programador/a Desarrollador/a de Software y Asistente de informática. 


\begin{tabular}{|c|c|c|c|c|}
\hline \multirow{2}{*}{ OCUPACIÓN/PROFESIÓN/TRABAJO } & \multicolumn{2}{|c|}{ CONURBANO BONAERENSE } & \multicolumn{2}{|c|}{ CORRIENTES } \\
\hline & VARONES & MUJERES & VARONES & MUJERES \\
\hline Forestador/a & $55 \%$ & $39 \%$ & $57 \%$ & $27 \%$ \\
\hline Albañil & $45 \%$ & $33 \%$ & $43 \%$ & $40 \%$ \\
\hline Operador/a de sierras & $52 \%$ & $33 \%$ & $48 \%$ & $40 \%$ \\
\hline Administrativo/a & $77 \%$ & $97 \%$ & $78 \%$ & $93 \%$ \\
\hline Gerente & $77 \%$ & $97 \%$ & $83 \%$ & $93 \%$ \\
\hline Guía de turismo & $71 \%$ & $97 \%$ & $91 \%$ & $80 \%$ \\
\hline Cocinero/a & $65 \%$ & $91 \%$ & $83 \%$ & $100 \%$ \\
\hline Técnico/a de laboratorio & $68 \%$ & $82 \%$ & $87 \%$ & $87 \%$ \\
\hline Obrero/a rural & $55 \%$ & $45 \%$ & $48 \%$ & $20 \%$ \\
\hline Operador/a de maquinaria & $61 \%$ & $64 \%$ & $65 \%$ & $27 \%$ \\
\hline Podador/a & $55 \%$ & $55 \%$ & $74 \%$ & $60 \%$ \\
\hline Operador/a técnico/a de campo (boca pozo petróleo) & $52 \%$ & $46 \%$ & $57 \%$ & $20 \%$ \\
\hline Técnico/a en mantenimiento eléctrico & $68 \%$ & $61 \%$ & $65 \%$ & $53 \%$ \\
\hline Técnico/a en mantenimiento mecánico & $65 \%$ & $42 \%$ & $61 \%$ & $47 \%$ \\
\hline
\end{tabular}

Fuente: elaboración propia a partir de datos de encuestas aplicadas a estudiantes de Centros de Formación Profesional.

No obstante, en varias de estas ocupaciones encontramos diferencias claras entre varones y mujeres en ambas regiones, con mayores porcentajes de percepciones no estereotipadas entre las mujeres: Asistente de informática, Cocinero/a, Administrativo/a, Gerente ${ }^{18}$. También se da el caso opuesto: en la mayoría de las ocupaciones relacionadas con el trabajo manual, poco calificado y que requiere esfuerzo físico el porcentaje de percepciones no estereotipadas baja claramente. Pero en este caso, en varias de ellas son los varones quienes opinan en mayor porcentaje que pueden ser desempeñadas tan bien por varones como por mujeres, en ambas regiones (Forestador, Obrero rural), o en una de ellas ${ }^{19}$.

En lo que respecta al principio de jerarquización ligado a lo masculino, persiste el cambio de tendencia en la comparación entre regiones, aunque en este caso es más clara la diferenciación entre varones y mujeres en ambas regiones, más acentuada en el rechazo a la afirmación «Las mujeres son mejores que los varones para desempeñarse en trabajos en los que tienen que recibir órdenes» (61\% de rechazo en las estudiantes del Conurbano Sur; $67 \%$ en las de Corrientes, contra $26 \%$ y $39 \%$ en los varones de cada región). Nuevamente, es muy bajo el porcentaje de percepciones no estereotipadas por género en los varones del Conurbano Sur. Por otra parte, si bien entre las mujeres de ambas regiones es mayoritario el porcentaje que rechaza las visiones estereotipadas, hay una diferencia considerable con las estudiantes mujeres de EST del Conurbano Sur, que tenían porcentajes de rechazo del 89\% y $76 \%$ en estos ítems. Esto nos habla de lo arraigado que sigue estando aún en muchas mujeres, la naturalización de la subordinación por género.

Por último, en referencia a los estereotipos acerca de la división del trabajo doméstico también encontramos, como en EST, un contraste entre una visión más igualitaria en relación al cuidado de los/ as hijos/as -ampliamente apoyada por la gran mayoría de los/as encuestados/as- y la persistencia,

18 En otras de estas ocupaciones, las tendencias no resultan tan claras, presentando diferencias por género sólo en una región (y no siempre la misma).

19 Albañil, Operador de Sierras en el Conurbano Sur; Operador técnico de pozo de petróleo, Operador de maquinaria y Podador en Corrientes. 
particularmente entre los varones, de la idea del cuidado del hogar como responsabilidad de las mujeres. En contraste, este último estereotipo es rechazado por un porcentaje importante de mujeres en ambas regiones (73\% en Conurbano Sur y $80 \%$ en Corrientes). Se advierte nuevamente el cambio en la dirección de las diferencias entre regiones en relación con la EST: los porcentajes de percepciones no estereotipadas son mayores en Corrientes que en el Conurbano Sur, aunque la brecha no es amplia.

¿Cómo explicar el contraste entre regiones que advertimos entre los/as estudiantes de EST y de FP? Entre los primeros, hemos notado una mayor persistencia de una visión tradicional entre los/as estudiantes correntino/as; en cambio, esta tendencia es totalmente opuesta entre los/as segundos/as, donde se destaca la fuerte persistencia de estereotipos en relación a la división sexual del trabajo particularmente entre los varones del Conurbano Bonaerense. Nuestra hipótesis -que, aunque fundada en los datos deberá ser corroborada específicamente en posteriores investigaciones- es que esto tiene que ver con las diferencias generacionales y sociales en los/as estudiantes de estos dos niveles.

Por un lado, entre los estudiantes de FP del Conurbano Sur predomina la población adulta (cerca del 70\% de los varones y el $84 \%$ de las mujeres de la muestra tiene más de 24 años). Esto contrasta con Corrientes, donde se observa una juvenilización de la matricula (el 57\% de los varones y el 40\% de las mujeres de la muestra se agrupa en la franja entre los 18 y 24 años de edad). Los estudiantes de EST, en cambio, en ambas jurisdicciones se ubican en la franja de 16 a 18 años. Ahora bien, como ya hemos señalado, la discusión pública de las desigualdades de género y los cambios culturales asociados se ha acelerado en los últimos años en la Argentina -particularmente en la Capital Federal y zonas de influencia-, afectando particularmente a las generaciones jóvenes -y mucho más a las mujeres jóvenes, como se refleja en los datos de EST del Conurbano Sur-.

La idea de generación, tal como fuera acuñada por Mannheim, implica que los nacidos en determinado momento histórico - particularmente en períodos de cambio significativo- enfrentan durante su juventud condiciones diferentes de las que enfrentaron sus padres, debiendo por lo tanto reinventar las reglas (Woodman y Wyn, 2015). Como señalan Margulis y Urresti (2008: 18): «Cada generación puede ser considerada, hasta cierto punto, como perteneciente a una cultura diferente, en la medida en que incorpora en su socialización nuevos códigos y destrezas, lenguajes y formas de percibir, de apreciar, clasificar y distinguir». El concepto de generación es pertinente en relación al género, dados los acelerados cambios culturales que al respecto han ocurrido en Argentina. En tal sentido, el discurso y las discusiones sociales en torno a las desigualdades de género que circulan en la actualidad en el país difieren sobre manera de las existentes unos pocos años atrás, poniéndose en cuestión aspectos que antes eran naturalizados.

Algunos indicios de esto hemos encontrado en los grupos focales de especialidades «tradicionalmente masculinas» del Conurbano Sur. Allí, los estudiantes de mayor edad referían lo que les cuesta constatar que las mujeres ocupan progresivamente empleos que tradicionalmente eran masculinos y cómo los nuevos modos de presencia de la mujer en el mercado laboral conllevan cambios importantes en las relaciones de género también al interior del hogar.

«Es muy jodido en la cabera de un tipo de 65... la mujer es mujer, y eso significa que si trabaja te roba el trabajo. Eso yo lo veo mal. Hay mujeres muy capacitadas, más que los hombres. (...) 


\begin{abstract}
En mi casa toma la decisión el hombre, no la mujer, mi hermana y mi vieja levantaban la mesa... venis de una tradición machista. Pero lo ves, ella [su esposa, que empezó a trabajar hace unos pocos años] como se desarrolló como persona, como mujer...». (Grupo focal en Curso de Constucciones, Conurbano Sur).
\end{abstract}

Poniendo entonces en vinculación el análisis cuantitativo con los datos de los grupos focales, advertimos también -como en el caso de la EST-, una naturalización de las desigualdades de género en el mercado laboral. Pero los/as estudiantes de FP tienen una mayor experiencia concreta en el mundo del trabajo, ya que la mayoría de ellos/as está inserto en el mercado, a diferencia de los/as estudiantes del secundario. En tal sentido, registran y mencionan diferencias de género que han vivenciado. No obstante, tales diferencias no son percibidas como desigualdades, sino como diferencias entre sectores de actividad: mientras en algunos sectores los varones tienen mayores oportunidades, en otros las tienen las mujeres, naturalizando entonces la segregación horizontal. Esto coincide con el análisis cuantitativo, donde vimos que el rechazo a las afirmaciones que reflejan el principio de separación es en todos los casos inferior al 50\%, con porcentajes muy bajos entre los varones del Conurbano Sur.

Nuevamente, estas diferencias son legitimadas en tanto se considera que hombres y mujeres tienen atributos y capacidades diferentes. En esto, advertimos continuidad con la discusión del apartado anterior: las mujeres son más cumplidoras, más prolijas, más ordenadas. Los varones son más adecuados para trabajos que requieran despliegue físico o capacidades técnicas específicas. En los grupos focales -tanto de varones como de mujeres- correspondientes a especialidades tradicionalmente asociadas a lo masculino aparece un nuevo elemento, no presente entre los/as jóvenes de EST: la idea de que las mujeres «no se animan», «tienen miedo» de asumir tareas que tienen un mayor componente físico o que suponen algún tipo de riesgo. Frente a esta situación -referida tanto por varones como mujeres-, los primeros despliegan cierta «tutela» sobre sus compañeras mujeres, asumiendo las actividades que a ellas les resultan más complicadas. Estereotipos arraigados sobre la «debilidad» de las mujeres que tienen que ser asistidas por los varones se ponen así en escena cotidianamente en estos cursos.

\begin{abstract}
"Estudiante 1: No sé, es como que tratan a la mujer con mucho cuidado, de que no te dé la corriente, de que no te quemes, que no quedes pegada... no sé es como que nos tienen cuidadas, cómo decirte... Inclusive nosotras mismas... a mí por lo menos me costaba el tema de la corriente. Igual ellos nos decian no tengas miedo, hacélo y asi y hasta que te agarra confianza». (Grupo focal de mujeres de Informática - Curso de Reparación de PC, Corrientes).
\end{abstract}

En contraposición con estas dinámicas reproductoras, en el Conurbano Bonaerense, en el curso de «Manipulación de alimentos», con amplia mayoría de mujeres, las estudiantes mencionan que las discusiones en el curso llevaron a desnaturalizar diferencias de género y a darles herramientas para abordar problemáticas de género, tales como violencia contra la mujer y discriminación en el mercado laboral. Volvemos a encontrar en el caso de la FP el potencial que tienen las instituciones de ETP para poner en discusión estereotipos arraigados. En los casos en estudio, hemos encontrado esto en cursos con mayoría de presencia femenina. Pero es un tema que necesita ser investigado más en profundidad, ampliando las comparaciones entre instituciones. 


\section{Conclusiones}

A partir de la constatación de las desigualdades de género que aún persisten en la ETP en Argentina, que se manifiestan en un bajo nivel de matriculación de mujeres en la EST y una segmentación por género entre especialidades tanto en EST como en FP, nos preguntábamos al comienzo de este artículo por los motivos que orientan tales decisiones educativas. La motivación instrumental de mejorar las propias oportunidades de acceso al empleo -o de lograr una mejor posición en el mercado laboral, en el caso de la FP-aparece como la más recurrente en ambos niveles.

Luego, aparecen motivaciones diferenciadas por nivel, por región y por género: en la EST, en el caso del Conurbano Bonaerense, es importante la percepción de que la educación técnica ofrece una buena preparación para los estudios universitarios, en especial para determinadas carreras. Esto pesa más en las mujeres que en los varones, reflejando en ellas una mayor preocupación por la continuidad educativa, que ya ha sido ampliamente discutida por la literatura. En Corrientes, en cambio, los problemas de empleo que experimentan los/as jóvenes y ciertas limitaciones de la oferta educativa en el interior de la provincia pone al empleo en el centro de las motivaciones de varones y mujeres y relega la importancia de la apuesta por los estudios universitarios.

En la FP, en Corrientes y más aún en las mujeres, aumenta el peso de los motivos expresivos (el «gusto» por la práctica y la satisfacción por el tipo de aprendizajes logrados). Los grupos focales muestran en ambas regiones que para algunas mujeres y también varones de mayor edad, los cursos funcionan como un espacio valorado de sociabilidad.

Las motivaciones expresivas (el «gusto» por la actividad) parecen tener más peso en los estudiantes de EST al elegir la especialidad. Esto nos indica que, como discutiéramos en el marco teórico, las elecciones en relación a la ETP no son meramente instrumentales, orientadas por el cálculo costo-beneficio (aunque este tipo de motivación es muy importante), sino que aparecen elementos emocionales y también modelos de identificación significativos para los/as estudiantes. Hemos presentado indicios acerca de la importancia de las orientaciones y ejemplos familiares, como así también del efecto de las estrategias y culturas institucionales en la toma de decisiones - particularmente de los/as jóvenes de EST- que perpetúan las desigualdades de género en la ETP. Como señalan las teorías de género, instituciones como la familia, la educación y el mercado laboral producen y transmiten representaciones y prácticas que están en la base de la perpetuación de desigualdades genéricas.

En este marco, en el texto nos hemos preguntado por la vigencia entre los estudiantes de EST de estereotipos en torno a la división sexual del trabajo, en un contexto nacional de acelerado cambio en los imaginarios de género. El análisis realizado muestra la importancia de una perspectiva multidimensional para captar un escenario heterogéneo y en transformación: al mismo tiempo que hemos encontrado grupos con un fuerte rechazo a tales estereotipos - entre los que se destacan las jóvenes estudiantes de EST del Conurbano Bonaerense-, hemos constatado la persistencia de los mismos en otras poblaciones -hay mayor porcentaje de percepciones estereotipadas en general en varones que en mujeres; y grupos con una clara preponderancia de visiones tradicionales, como por ejemplo los estudiantes varones de FP del Conurbano Sur-. En estas diferencias intervienen tanto distinciones de género como territoriales, evidenciando las diferencias culturales y socio-económicas que caracterizan a la Argentina. El contraste en el Conurbano Sur entre las perspectivas altamente tradicionales de los estudiantes varones de FP y más 
moderadas de los de EST (sobre todo en comparación con sus pares de Corrientes) nos llevó a formular la hipótesis acerca del peso de la generación en la persistencia o transformación de estereotipos de género, aspecto a ser profundizado en posteriores investigaciones.

\section{Referencias bibliográficas}

Anzorena, Claudia (2013): "División sexual del trabajo: varones públicos, mujeres domésticas" en: Mujeres en la trama del Estado. Una lectura feminista de las políticas públicas. Mendoza: EDIUNC.

Archer, Louise; DeWitt, Jennifer; Osborne, Jonathan; Dillon, Justin; Willis, Beatrice y Wong, Billy (2013): “Not Girly, Not Sexy, Not Glamorous: Primary School Girls' and Parents' Constructions of Science Aspirations". Pedagogy, Culture \& Society, 21 (1), 171-194. DOI: https://doi.org/10.1080/14681366.20 12.748676.

Archer, Louise; Moote, Julie; Macleod, Emily y DeWitt, Jennifer. (2020): “ASPIRES 2: Young People’s Science and Career Aspirations, age 10-19”. UCL Discovery.

Bloj, Cristina (2017). Trayectorias de mujeres Educación técnico-profesional y trabajo en la Argentina. Santiago de Chile: Naciones Unidas/CEPAL (en línea). https://www.cepal.org/es/publicaciones/41230-trayectorias-mujeres-educacion-tecnico-profesional-trabajo-la-argentina.

Bourdieu, Pierre (1999). La dominación masculina. Barcelona: Editorial Anagrama.

Busso, Mariana y Pérez, Pablo (2019): "El velo meritocrático: inequidades en la inserción laboral de jóvenes durante el gobierno de Cambiemos". RevIISE: Revista de Ciencias Sociales y Humanas, 13 (13). 133-145.

Butler, Judith (2001). El género en disputa. El feminismo y la subversión de la identidad. México: Paidós.

Evans, Karen (2006): “Achieving Equity Through 'Gender Autonomy': The Challenges for VET Policy and Practice". Journal of vocational education and training, 58 (4), 393-408. DOI: https://doi. org/10.1080/13636820601005453.

Gallart, María Antonia (2006). La escuela técnica industrial en Argentina: ¿un modelo para armar? Montevideo: CINTERFOR-OIT.

Guber, Rosana y Soprano, Germán (2001): “La dimensión cultural de la crisis en Corrientes” en: Análisis de los factores intervinientes en la crisis del Estado en la provincia de Corrientes. Corrientes: Universidad Nacional del Nordeste.

Gutierrez Esteban, Prudencia e Ibáñez Ibáñez, Patricia (2013): “¿Cómo se transmiten los estereotipos culturales y sexistas a través de las imágenes de las TIC en los libros de texto?”. Enseñanza \& Teaching: Revista Interuniversitaria de Didáctica, 31 (1), 109-125.

INET (2017). Las mujeres en la secundaria técnica: diagnóstico de una desigualdad persistente (en línea). http://www.inet.edu.ar/wp-content/uploads/2019/03/Las-mujeres-en-la-ETP.pdf, consultado el 29 de enero de 2020. 
INET (2019). Mujeres en la ETP: Desigualdades y oportunidades (en línea). http://www.inet.edu.ar/ wp-content/uploads/2018/03/Mujeres-en-la-ETP-Desigualdades-y-oportunidades.pdf,. consultado el 29 de enero de 2020.

Jacinto, Claudia (2015): "Nuevas lógicas en la formación profesional en Argentina Redefiniendo lo educativo, lo laboral y lo social". Perfiles educativos, 37 (148), 120-137. DOI: https://doi.org/10.1016/j. pe.2015.11.011.

Margulis, Mario y Urresti, Marcelo (2008). La juventud es más que una palabra: ensaios sobre cultura y juventud. $3^{\mathrm{a}}$ ed. Buenos Aires: Editorial Biblos.

Martínez García, José Saturnino y Merino, Rafael (2011): "Formación profesional y desigualdad de oportunidades educativas por clase". Témpora: Revista de historia y sociología de la educación, 14, 13-37.

Martínez García, José Saturnino (2017): "Sobrecualificación de los titulados universitarios y movilidad social”. Papers. Revista de Sociologia, 102 (1), 29-52. DOI: http://dx.doi.org/10.5565/rev/papers.2225.

Martínez García, José Saturnino (2019): “Género y educación: brecha inversa y segregación” en: Equidad, educación y género. Madrid: Dykinson.

Merino, Rafael; Martínez García, José y Valls, Ona (2020): "Efectos secundarios y motivaciones de las personas jóvenes para escoger Formación Profesional”. Papers. Revista de Sociologia, 105 (2), 259-277. DOI: http://dx.doi.org/10.5565/rev/papers.2776.

Moote, Julie; Archer, Louise; DeWitt, Jennifer y MacLeod, Emily (2020): “Comparing Students’ Engineering and Science Aspirations From Age 10 to 16: Investigating the Role of Gender, Ethnicity, Cultural Capital, and Attitudinal Factors". Journal of Engineering Education, 109 (1), 34-51. DOI: https://doi. org/10.1002/jee.20302.

Millet, Kate (1996). Política sexual. Madrid: Cátedra.

Millenaar, Verónica y Jacinto, Claudia (2015): “Desigualdad social y género en las trayectorias laborales de jóvenes de sectores populares. El lugar de los dispositivos de inserción" en René Unda Lara, Liliana Mayer, Daniel Llanos Erazo (coords.): Socialización escolar. Procesos, experiencias y trayectos. Ecuador: Universidad Politécnica Salesiana.

Millenaar, Verónica (2017): "Políticas de empleo con enfoque de género: formación laboral en oficios no tradicionales para mujeres”. Cadernos Pagu, 51. DOI: https://doi.org/10.1590/18094449201700510014.

Millenaar, Verónica (2019): "Masculinidades en la formación profesional: expectativas y sentidos del trabajo en un contexto de incertidumbre laboral". Descentrada, Revista interdisciplinaria de feminismos y género, 3 (1) DOI: https://doi.org/10.24215/25457284e069.

Organización Internacional del Trabajo (2014). Diagnóstico Igualdad de género en los Institutos de Formación Profesional de América Centraly República Dominicana. OIT.

Pérez Moreno, Elena Silvia (2012). El lugar de las alumnas dentro de una escuela técnica secundaria de la ciudad de córdoba. II Congreso Interdisciplinario Género y sociedad. Lo personal es político. Córdoba. Universidad Nacional de Córdoba. 
PNUD (2011). Aportes para el Desarrollo Humano en Argentina. Buenos Aires.

Rubin, Gayle (1986): “El tráfico de mujeres: notas sobre la ‘economía política’ del sexo”. Nueva antropología, 8 (30), 95-145.

Seoane, Viviana (2012). Sexismo y androcentrismo en la escuela técnica: experiencias de mujeres jóvenes en torno a la sexualidad, el género y la condición juvenil. VII Jornadas de Sociología de la UNLP. La Plata: Universidad Nacional de La Plata.

Scott, Joan (1999): "El género: una categoría útil para el análisis histórico" en Marysa Navarro y Catharine Stimpson (comps.): Sexualidad, género y roles sexuales. Buenos Aires: Fondo de Cultura Económica.

Subirats, Marina (2016): "De los dispositivos selectivos en la educación: el caso del sexismo". Revista de la Asociación de Sociología de la Educación, 9 (1), 22-36.

Tarabini, Aina y Curran, Marta (2015): "El efecto de la clase social en las decisiones educativas: un análisis de las oportunidades, creencias y deseos educativos de los jóvenes". Revista de Investigación en Educación, $13(1), 7-26$.

Wainerman, Catalina (2005). La vida cotidiana en las nuevas familias ¿̇na revolución estancada? Buenos Aires: Lumiere.

Woodman, Dan y Wyn, Johanna (2015). Youth and Generation: Rethinking Change and Inequality in the Lives of Young People. Londres: Sage Publications.

\section{Notas biográficas}

Ada Freytes Frey es Licenciada en Sociología (Universidad del Salvador) y Doctoranda de la Facultad de Ciencias Sociales (UBA). Actualmente es Profesora Regular de la Universidad Nacional Arturo Jauretche (UNAJ) y en la Universidad Nacional de Avellaneda (UNDAV), Argentina. Es investigadora en ambas instituciones, integrando el Observatorio de Calificaciones Laborales (OCAL) en la primera y el Módulo de Políticas Educativas en el Observatorio de Políticas Púlicas en la UNDAV. Sus temas de interés son: Juventudes, Subjetividades, Educación y Trabajo, Políticas públicas y Género.

Orcid: https://orcid.org/0000-0001-5793-7046.

Pablo Barbetti es Licenciado en Relaciones Industriales, Magister en Desarrollo Social (UNNE) y Doctorando de la Facultad de Humanidades de la Universidad Nacional de Misiones (UNM). Actualmente es Profesor Regular en carreras de grado y posgrado de la Universidad Nacional del Nordeste (Argentina). Integra grupos de investigación en el Instituto de Investigaciones Educativas (Facultad de Humanidades) y en el Centro de Estudios Sociales (CES-UNNE). Sus trabajos de investigación se inscriben en problemáticas vinculadas con el área: Juventudes, Educación y Trabajo y Políticas Públicas.

Orcid: https:// orcid.org/0000-0003-3687-8918. 